\title{
The First Results of Extended Newborn Screening in Slovakia-Differences between the Majority and the Roma Ethnic Group
}

\author{
Svetozár Dluholucký ${ }^{1,2, *}$ and Mária Knapková ${ }^{1}$ \\ 1 Newborn Screening Centre of Slovak Republic, Children Faculty Hospital, 97409 Banská Bystrica, \\ Slovak Republic; maria.knapkova@dfnbb.sk \\ 2 Faculty of Health, Slovak Medical University in Bratislava, Sládkovičova 21, 97405 Banská Bystrica, \\ Slovak Republic \\ * Correspondence: svetozar.dluholucky@szu.sk; Tel.: +42-190-544-9038; Fax: +42-148-472-6566
}

Received: 6 February 2017; Accepted: 28 August 2017; Published: 30 August 2017

\begin{abstract}
The authors present the first results of the National Extended Newborn Screening (ENS) in Slovakia in the majority (M) and the Roma (R) ethnic populations. A follow-up of ethnicity has been introduced in newborn screening for cystic fibrosis (NSCF) and afterwards to the entire ENS program comprising of 23 inborn errors of metabolism (IEM). In 2013-2015, a total of 165,648 newborns were investigated in ENS, 23,321 of them (14\%) were the R ethnic group, a total of 313 positive cases were discovered (total ENS prevalence $=1: 529, \mathrm{M}=1: 758, \mathrm{R}=1: 198$ ). In the $\mathrm{R}$ ethnic group, there was a slightly higher prevalence of congenital hypothyroidism $(\mathrm{CH})$, only one case of $\mathrm{CF}$, and no cases of congenital adrenal hyperplasia (CAH) in the R ethnic group. The ENS prevalence of IEM detected by MS/MS was significantly higher in the $R$ ethnic group than in $M$ group ( $M=1: 1670$ vs. $\mathrm{R}=1: 234$, OR:7.13). Significant differences in the prevalence of individual types of IEM were also found. While PKU and other aminoaciduria and organic acidurias dominate in the M group, the fatty acid oxidation disorders (MCAD, SCAD) and carnitine defects (CUD) were more frequent in the R newborn group. Despite the preliminary nature of the results, an ethnic approach to ENS enables the recording of the ethnic differences in the screen prevalence of individual disorders, which would not be apparent without this approach.
\end{abstract}

Keywords: extended newborn screening; ethnic screening differences; Roma ethnicity

\section{Introduction}

Newborn screening (NBS) in Slovakia began in 1985 with the detection of congenital hypothyroidism (CH), followed by phenylketonuria (PKU) in 1995, and congenital adrenal hyperplasia $(\mathrm{CAH})$ in 2003 [1]. During a pilot study, before the screening was extended to include cystic fibrosis (NSCF-newborn screening for cystic fibrosis), an elevated level of the immunoreactive trypsinogen (IRT) screening test was found in as many as $32 \%$ of the newborn babies in the Roma ethnic (R) group, compared to the majority (M) population. This necessitated the establishment of different cut-off limits for the majority and the Roma population and hence the recording of the ethnicity of the newborn population. The NSCF was launched nationwide in 2009 and these results were published previously [2,3]. From 1 January 2013, the newborn screening was extended by the introduction of a tandem mass spectrometry (MS/MS) for 20 inborn errors of metabolism (IEM). The monitoring of the ethnicity of the population, initially for the needs of NSCF, has also allowed us to evaluate of the total and ethnic incidence of other IEM. The aim of this work is to present the first results of the NS from 2013 to 2015. 


\section{Materials and Methods}

The extended newborn screening (ENS) was carried out in a Neonatal Screening Center at the Children Faculty Hospital Banská Bystrica, Slovakia. From 2013, the ENS included 20 types of IEM, as shown in Table 1, using the MS/MS method, 10 of them as an official national NS confirmed by Ministry of Health of Slovak Republic and another 10 as a pilot prospective study. Together with $\mathrm{CH}, \mathrm{CAH}$, and $\mathrm{CF}$, this represents a total of 23 disorders. The paper presents the results obtained from 1 January 2013 to 31 December 2015. All the cases presented, detected in the ENS have been diagnostically verified and definitively confirmed by the specialized regional centers for metabolic diseases, including genetic testing.

Table 1. Spectrum of IEMs in extended newborn MS/MS screening since 1 January 2013.

\begin{tabular}{cc}
\hline IEM Reg & Abb. \\
\hline phenylketonuria/hyperphenylalaninaemia & PKU/HPA \\
maple syrup urine disease & MSUD \\
isovaleric acidemia & IVA \\
glutaric acidemia type I & GA-I \\
medium chain acyl-CoA Dehydrogenase Deficiency & MCADD \\
very long chain acyl-CoA Dehydrogenase Deficiency & VLCADD \\
long chain hydrxoyacyl-CoA Dehydrogenase Deficiency & LCHADD \\
carnitine palmitoyl tranferase 1 deficiency & CPT-1 \\
carnitine palmitoyl tranferase 2 deficienc & CPT-2 \\
carnitine-acylcarnitine translocase deficiency & CACT \\
IEM pil. Study & \\
tyrosinemia types I and II & Tyr I, II \\
hypermethioninaemia & Met \\
propionic acidaemia & PA \\
methylmalonic acidaemia & MMA \\
citrullinaemia & Cit \\
argininaemia & Arg \\
Short chain acyl CoA Dehydrogenase Deficiency & SCADD \\
3-methyl crotonyl CoA carboxylase deficiency & 3-MCC \\
3-hydroxymethylglutaryl CoA dehydrogenase deficiency & HMG \\
carnitine uptake defect & CUD \\
\hline
\end{tabular}

\section{Results}

The ENS results are comprehensively presented in Table 2.

During the three years of screening (2013-2015), a total of 165,648 newborns were tested which, according to the results of the National Statistical Register of births, is virtually $100 \%$ of the population of live births. Of these, 25,321 (15.4\%) were Roma (R) children and 140,327 (84.7\%) children of the majority (M) ethnicity. In the group of IEM, there were 192 cases detected in the whole spectrum of disorders, e.g., the overall IEM incidence is 1:863. Of these, 84 cases were in the $M$ group (1:1671) and 108 cases in the R group (1:234). Eighty seven cases of $\mathrm{CH}$ (incidence 1:1904) were detected, 68 cases were in the M group (1:2063) and 19 cases in the R group (1:1333)_odds ratio:1.35. Ten cases of CAH were detected (1:16,565), all of them in the M group. No case of CAH was detected in the R group. Similarly, from 24 detected cases of CF (1:6902), 23 cases were in the M group (1:6101), and only one case was in the R group. Overall, the ENS detected and confirmed the 313 positive cases, which the screening incidence in total population is 1:529. After ethnic groups, the overall incidence in M group is 1:758, and in the $\mathrm{R}$ group is 1:197. The difference between $\mathrm{M}$ and $\mathrm{R}$ groups is even more obvious when these data are presented as prevalence (n/104 Table 3).

IEM prevalence, as well as the total screening prevalence, in group $\mathrm{R}$ is nearly four-fold greater when compared to group $\mathrm{M}$, whereas the prevalence of $\mathrm{CF}$ and $\mathrm{CAH}$ is lower in the Roma population. 
The differences in IEM type between the groups $\mathrm{M}$ and $\mathrm{R}$ are even more significant. The most common disorders of the whole set (Table 4) are SCAD, PKU, CUD, and MCAD.

Table 2. Results of extended newborn screening in Slovakia 2013-2015.

\begin{tabular}{ccccc}
\hline Data & Total Pop. & Major & Roma & OR \\
\hline Absol.n. & 165,648 & 140,327 & 25,321 & \\
M/R\% & 100 & $84.70 \%$ & $14.30 \%$ & \\
IEMabs. & 192 & 84 & 108 & \\
incid. & 862 & 1670 & 234 & \\
prev.10 & 11.59 & 5.98 & 42.65 & OR:7.13 \\
CH & 87 & 68 & 19 & \\
incid. & 1904 & 2063 & 1333 & \\
prev.10 & 5.25 & 4.84 & 6.56 & OR:1.35 \\
CAH & 10 & 10 & 0 & \\
incid. & 16,565 & 16,565 & $<25,321$ & \\
prev.10 & 0.6 & 0.71 & 0 & \\
CF & 24 & 23 & 1 & \\
incid. & 6902 & 6101 & 25,321 & \\
prev.10 & 1.45 & 1.64 & 0.39 & \\
total abs & 313 & 185 & 128 & \\
tot.incid. & 529 & 758 & 197 & \\
prev.10 & 18.9 & 13.2 & 50.5 & OR:3.83 \\
\hline
\end{tabular}

Table 3. Total and ethnic prevalence of screening disorders (n to $10^{4}$ ).

\begin{tabular}{cccc}
\hline Prev.10 $^{\mathbf{4}}$ & Major & Roma & Total \\
\hline IEM & 5.98 & 42.65 & 11.59 \\
CH & 4.84 & 6.56 & 5.25 \\
CAH & 0.71 & 0 & 0.6 \\
CF & 1.64 & 0.39 & 1.45 \\
Total & 13.2 & 50.5 & 18.9 \\
\hline
\end{tabular}

Table 4. Absolute numbers of IEMs detected by newborn screening after ethnicity.

\begin{tabular}{cccc}
\hline Disorder & Major & Roma & Total \\
\hline PKU & 32 & 8 & 40 \\
MCADD & 6 & 9 & 15 \\
GA-1 & 2 & 0 & 2 \\
LCHADD & 1 & 0 & 1 \\
IVA & 1 & 0 & 1 \\
MSUD & 1 & 0 & 1 \\
Met & 1 & 0 & 1 \\
Tyr & 4 & 2 & 6 \\
3MCCD & 8 & 1 & 9 \\
MMA & 2 & 1 & 3 \\
CUD & 20 & 16 & 36 \\
Cit & 2 & 0 & 2 \\
SCADD & 2 & 69 & 71 \\
PA & 0 & 2 & 2 \\
NKH & 1 & 0 & 1 \\
Gal & 1 & 0 & 1 \\
Total & 84 & 108 & 192 \\
\hline
\end{tabular}

${ }^{*}$ Nonketotic hyperglycinaemia. 
When the group is identified by ethnicity, the distribution of IEM is even more obvious. PKU is the most common disorder in the majority $(\mathrm{M})$ ethnic group, followed by CUD and there is a wide range of IEMs (Figure 1). The most common disorder in the R ethnic group is SCAD, followed by CUD, MCAD, and PKU in fourth place (Figure 2). In this ethnic group, the spectrum of IEMs is not as diverse as in $\mathrm{M}$ ethnic group.

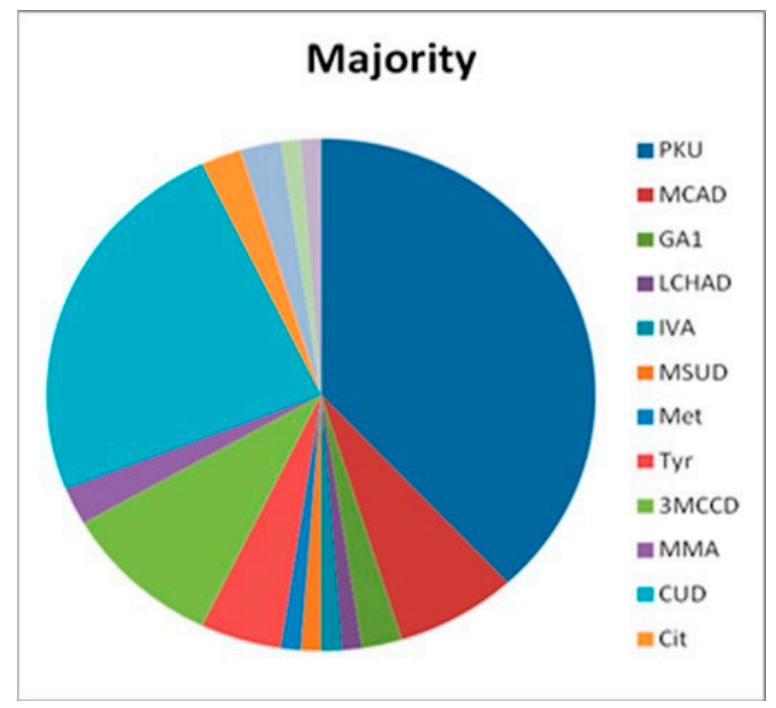

Figure 1. Spectrum of IEMs in the majority newborns.

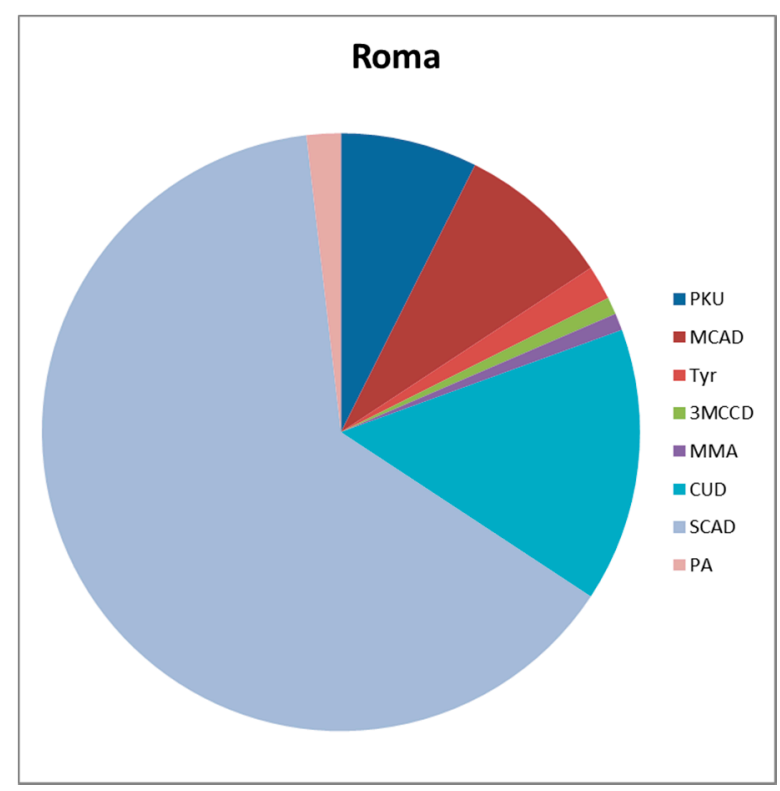

Figure 2. Spectrum of IEMs in the Roma newborns.

These differences become more obvious when they are converted to prevalence (Table 5). 
Table 5. Prevalence (n to 104) of the most frequent IEMs in total newborn population and after the ethnicity.

\begin{tabular}{cccc}
\hline IEM & Majority & Roma & Total \\
\hline PKU & 2.28 & 3.016 & 2.41 \\
MCADD & 0.42 & 3.035 & 0.9 \\
CUD & 1.43 & 6.32 & 2.17 \\
SCADD & 0.14 & 27.25 & 4.29 \\
Total & 5.99 & 42.65 & 11.59 \\
\hline
\end{tabular}

\section{Discussion}

The identification of the ethnicity of newborns was required because the NSCF showed significantly higher IRT values in one ethnic group and thus the need of different cut-off limits in Roma newborns [2,3]. This practice was introduced following approval by the ethics committees of the Children Faculty Hospital Banská Bystrica and the Slovak Ministry of Health. The second phase allowed for the expansion in the range of IEM in the ENS, in addition to the officially planned 10 IEMs, the MS/MS software enabled us to detect 10 other IEMs during the routine testing of the dry blood sample.

The entire spectrum of IEMs complies with Wilson-Jungner eligibility criteria for NS, and many were already included in the regular NS of several European countries [4,5] and in US NS [6].

The implementation of follow-up ethnicity during ENS brought us many new and unexpected results. Before 2013, results of NBS in Slovakia were evaluated for the whole newborn population. However at that time, the high incidence of $\mathrm{CH}$ in the Roma population in the eastern region of Slovakia was reported [7]. Anecdotal claims about the low incidence of CF in the Roma population in Slovakia did not occur, until the introduction of NSCF. At the same time, an elevated IRT value was been noted in African American newborns [8,9], and there were found to be differences in CF incidence in these ethnic groups [10]. Despite, the relation of significantly higher incidence of sudden infant death (SID [11]), which may be related to some IEMs [12,13], this has not yet been analyzed. Recent studies of the Roma population in Central Europe also point to differences in the Roma population in Slovakia in comparison to Roma populations of neighboring countries [14,15]. The Slovak Republic (SK), with its location in the center of Europe and five-million inhabitants, has a relatively homogeneous population of predominantly Caucasian ethnicity. The most significant autochthonous minority is the Roma ethnic group, representing about $10 \%$ of the population (absolutely approx. 500,000 people). Any differences in demographic data (e.g., infant mortality rate, under-five mortality rate, etc.) in this community has been attributed to disadvantaged social conditions and a different way of life [16].

Studies concerning the hereditary origin of these health issues are rare. Slovakian Roma children showed a significantly higher incidence of congenital glaucoma, which is rare even among the Roma populations of neighboring countries [14,17]. The ENS introduced in Slovakia in the first three years revealed marked differences in the occurrence of various disorders in the majority and the Roma ethnic group. Although these results are preliminary, they are roughly comparable with the results of the California study of the ethnic/racial differences in the prevalence of IEMs. Low or zero incidence of CF and CAH, and a contrasting high incidence of MCADD, SCADD, and CUD in the Slovak Roma population are both similar to California's findings in newborns from the Middle East and India [6]. Namely these regions are the provenance of the European Roma population $[14,15]$.

The second ENS issue discussed is the spectrum of IEMs to be included as part of newborn screening, and the effort to unify an approach $[4,5,18,19]$. Even in EU countries, the range of screened disorders varies from 4 to 30 IEMs [5]. In particular, NBS for CUD and SCADD is a matter of debate. Both these disorders have considerable variability in their incidence, heredity, clinical expression, symptoms, and the need for treatment [20-22]. An extraordinarily high screening incidence of these disorders has been found in our Roma group of newborns. This opens up a number of issues, notably: [1] What is the range of symptomatic and asymptomatic forms of identified cases of SCADD, 
are there differences in their genetic background between the majority and the Roma ethnic group? [2] Will the long-term ENS results confirm the differences found? [3] Will it be possible to differentiate the forms-especially SCADD and CUD—in terms of the need for continuous monitoring and therapeutic intervention? All of these questions will be solved by subsequent studies. However, now it is obvious that the high prevalence of the CUD and SCADD is sufficient reason to include them into regular ENS. Confirmation of accuracy of these steps can be expected from further results.

\section{Conclusions}

The ethnically evaluated ENS in Slovakia, after a short period of time, found significant differences in the incidence and prevalence of almost all disorders, especially in the IEM group, between the majority and Roma population of newborns, this was not revealed within the global evaluation study. The significance of the differences observed is that they allow us to focus purposefully on the curative and preventive care, especially for children living in socially disadvantaged areas. It also creates opportunities for further research into the etiopathogenesis of these differences.

Author Contributions: Svetozár Dluholucký conceptualized and designed the study, continuously followed the study and corrected the individual deviations in its course, drafted and finalized the manuscript and approved it for submission. Mária Knapková supervised the screening study, designed the data collection, supervised the data collection, critically reviewed the manuscript, and approved the final manuscript for submission.

Conflicts of Interest: The authors declare no conflict of interest.

\section{References}

1. Dluholucký, S.; Knapková, M. Newborn Screening in Slovakia-From 1985 till today. Acta Facult. Pharm. Univ. Comen. 2013, 60 (Suppl. 8), 32-37.

2. Dluholucký, S.; Knapková, M. Newborn screening in Slovakia-What news. In Proceedings of the 8th ISNS European Neonatal Screening Regional Meeting, Budapest, Hungary, 4-6 November 2012.

3. Dluholucký, S.; Knapková, M.; Záhorcová, M. First Results from Expanded Newborn Screening in the Slovak Republic. Acta Fac. Pharm. Univ. Comen. 2014, 1, 17-20. [CrossRef]

4. Loeber, J.G.; Burgard, P.; Cornel, M.C.; Rigter, T.; Weinreich, S.S.; Rupp, K.; Hoffmann, G.F.; Vittozzi, L. Newborn screening pro-grammes in Europe: Arguments and efforts regarding harmonization. Part 1—Blood spot to screening result. J. Inherit. Metab. Dis. 2012, 35, 603-611. [CrossRef] [PubMed]

5. Burgard, P.; Rupp, K.; Linder, M.; Haege, G.; Rigter, T.; Weinrich, S.S.; Loeber, J.G.; Taruscio, D.; Vittozzi, L.; Cornel, M.C.; et al. Newborn screening pro-grammes in Europe; arguments and efforts regarding harmonization. Part 2-From screening la-boratory results to treatment, follow-up and quality assurance. J. Inherit. Metab. Dis. 2012, 35, 613-625. [CrossRef] [PubMed]

6. Feuchtbaum, L.; Carter, J.; Dowray, S.; Currier, R.J. Lorey F Birth prevalence of disorders detectable through newborn screening by race/ethnicity. Genet. Med. 2012, 14, 1937-1945. [CrossRef] [PubMed]

7. Leščišinová, M.; Kúseková, M.; Sedlák, J.; Murková, V.; Langer, P.; Pavkovceková, O. Increased incidence of congenital hypothyroidism in gypsies in East Slovakia as compared with white population. Endocr. Exper. $1989,23,137-141$.

8. Giusti, R. Elevated IRT levels in African-American infants: Implica-tions for newborn screening in an ethnically diverse population. Pediatr. Pulmonol. 2008, 43, 638-641. [CrossRef] [PubMed]

9. Giusti, R.; Badgwell, A.; Iglesias, A.D. New York State Cystic Fibrosis Consortium: The Frist 2.5 Years of Experience with Cystic Fibrosis Newborn Screening in an Ethnically Diverse Population. Pediatrics 2007, 119, e460-e467. [CrossRef] [PubMed]

10. Endreffy, E.; Németh, K.; Fekete, G.; Gyurkovits, K.; Stankovics, J.; Szabó, Á.; Sólyom, E.; Dolinay, T.; Raskó, I.; László, A. Molecular Genetic Diagnostic Difficulties in Two Hungarian Gypsy Samples with Cystic Fibrosis. IJHG 2002, 2, 41-44.

11. Jablonský, P.M.; Dluholucký, S. Present status of SIDS in Central Slovakia. Eur. J. Pediatr. 1995, 154 (Suppl. 1), 278-279.

12. Bennett, M.J.; Gray, R.G.; Isherwood, D.M.; Murphy, N.; Pollitt, R.J. The diagnosis and biochemical investigation of a patient with short chain fatty acid oxidation defect. JIMD 1985, 8 (Suppl. 2), 135-136. 
13. Gallant, N.M.; Leydiker, K.; Tang, H.; Feuchtbaum, L.; Lorey, F.; Puckett, R.; Deignan, J.L.; Neidich, J.; Doorani, N.; Chang, E.; et al. Biochemical, molecular, and clinical characteristics of children with short chain acyl-CoA dehydrogenase deficiency detected by newborn screening in California. Mol. Genet. MeTab. 2012, 106, 55-61. [CrossRef] [PubMed]

14. Kalaydjieva, L.; Gresham, D.; Calafell, F. Genetic studies of the Roma (Gypsies): A review. BMC Med. Genet. 2001, 2, 5-17. [CrossRef] [PubMed]

15. Bartsocas, C.S.; Karayanni, C.; Tsipouras, P.; Baibas, E.; Bouloukos, A.; Papadatos, C. Genetic structure of the Greek gypsies. Clin. Genet. 1979, 15, 5-10. [CrossRef] [PubMed]

16. Ferák, V.; Siváková, D.; Kroupová, Z. Genetic-distance, geographic distance and migration between for villages of a single region in Slovakia. J. Hum. Evol. 1980, 9, 573-581. [CrossRef]

17. Genčík, A. Epidemiology and genetics of primary congenital glaucoma in Slovakia. Description of a form of primary congenital glaucoma in Gypsies with autosomal recessive inheritance and com-plete penetrance. Dev. Ophtalmol. 1989, 16, 76-115.

18. Pollitt, R.J. Introducing new screens: Why we are all doing different things? JIMD 2007, 30, 423-429. [CrossRef] [PubMed]

19. Plass, A.M.C.; van El, C.G.; Pieters, T.; Cornel, M.C. Neonatal Screening for Treatable and Untreatable Disorders: Prospective Parents' Opinions. Pediatrics 2009, 125, e99-e106. [CrossRef] [PubMed]

20. Engel, A.G.; Rebouche, C.J. Carnitine Metabolism and Inborn Errors. J. Inherit. Metab. Dis. 1984, 7, 38-43. [CrossRef] [PubMed]

21. Yang, L.L.; Huang, X.W.; Yang, J.B.; Zhou, X.L.; Huang, X.L.; Yang, R.L. Screening and diagnosis of chil-dren with primary carnitine deficiency in Zheijang Province. China HK J. Pediatr. 2013, 18, 167-173.

22. Van Maldegen, B.T.; Duran, M.; Wanders, R.J.A.; Niezen-Koning, K.E.; Hogeveen, M.; Ijlst, L.; Waterham, H.R.; Wijburg, F.A. Clinical, Biochemical, and Genetic Heterogeneity in Short-Chain Acyl-Coen-zyme A Dehydrogenase Deficiency. JAMA 2006, 296, 943-951. [CrossRef] [PubMed]

(C) 2017 by the authors. Licensee MDPI, Basel, Switzerland. This article is an open access article distributed under the terms and conditions of the Creative Commons Attribution (CC BY) license (http:/ / creativecommons.org/licenses/by/4.0/). 